\title{
Air-methane mixture ignition with Multi-Walled Carbon NanoTubes (MWCNTs) and comparison with spark ignition
}

\author{
A. Paolo Carluccia ${ }^{\mathrm{a}}$ L. Strafella*a \\ ${ }^{a}$ Departement of Innovation Engineering, University of Salento - Lecce 73100, Italy
}

\begin{abstract}
This paper presents the potentialities of a new ignition system based on exposition of multi-walled carbon nanotubes containing $75 \%$ in weight of ferrocene to a low-consumption flash camera. The experiments were performed in a constant-volume chamber equipped with an optical access, to allow the acquisition of high-speed camera images, and with a piezoresistive pressure sensor. The chamber was filled with an air-methane gaseous mixture and its combustion was triggered by flashing the nanotubes. The resulting combustion process was compared with the one obtained triggering the mixture ignition with a traditional spark plug. The combustion process was characterized for different air-methane ratios.

The results show that the ignition with nanotubes determines a higher combustion pressure gradient and a higher peak pressure than spark ignition for all the tested air-methane ratios. Furthermore, high-speed camera images show that the ignition with nanotubes leads to a more distributed homogeneous-like combustion and then a faster consumption of the air-methane mixture without the formation of a discernible flame front.
\end{abstract}

(C) 2015 The Authors. Published by Elsevier Ltd. This is an open access article under the CC BY-NC-ND license (http://creativecommons.org/licenses/by-nc-nd/4.0/).

Peer-review under responsibility of the Scientific Committee of ATI 2015

Keywords: Carbon nanotubes; SWCNTs; MWCNTs; Ignition; Spark ignition; Internal combustion engines

\section{Introduction}

The ignition of a traditional air-fuel mixture can be carried out with different sources of external energy, such as by means of an electric spark or compressing the mixture. Unfortunately, in the first case, a

\footnotetext{
* Corresponding author. Tel.: -39 0832 297320; fax: +39 0832297777

E-mail address: luciano.strafella@unisalento.it.
} 
relatively slow flame front originates from the spark and then propagates burning the air-fuel mixture; in the second case, the ignition process can be highly sensitive to operating conditions such as ambient temperature and pressure, especially when implementing alternative combustion strategies like lowtemperature combustion [1].

In order to solve these problems, a new ignition system is proposed taking advantage of ignition properties of carbon nanostructures when exposed to a low-consumption flash light source. In fact, nanostructures bonded with particles of an oxidant metal can quickly convert their internal chemical energy into thermal energy when they are exposed to a light source.

The first observation of this phenomenon, illustrated by Ajayan et al. in [2], concerned Single-Walled Carbon NanoTubes (SWCNTs), while other nanostructures such as Multi-Walled Carbon NanoTubes (MWCNTs) did not exhibit the ignition process. Afterwards, Bockrath et al. in [3] showed that other nanostructures containing carbon compounds synthesized on metal catalysts can ignite when exposed to a flash. Smits et al. in [4] confirmed that the ignition process can occur if nanoparticles of metallic impurities are present in SWCNTs. Chehroudi et al. in [5-10] suggested and patented the idea of using nanostructures as distributed ignition source in rocket and internal combustion engine applications. In this way, in fact, the combustion process could be controlled, in terms of ignition timing and mixture portion. Finally, Berkowitz and Oehlschlaeger in [11] have shown that SWCNTs (containing the 70\% iron by weight) introduced and mixed in an air-ethylene mixture inside a combustion chamber and exposed to the camera flash, can trigger the combustion process.

This paper proposes an ignition system for an air-methane mixture, based on the exposition of MultiWalled Carbon NanoTubes (MWCNTs) to the flash of a camera. The ignition agents (MWCNTs containing the $75 \%$ weight of ferrocene) have been added to the air-methane mixture and afterwards exposed to the flash. In order to evaluate the ignition effectiveness, the so obtained combustion process has been compared with the one obtained with a traditional spark plug. It was demonstrated that the combustion obtained photo-igniting MWCNTs with ferrocene determines a higher combustion pressure gradient and a higher peak pressure than spark ignition for all the tested air-methane ratios. Moreover, a more homogeneous combustion process is observed instead of the classic flame front propagation.

\begin{tabular}{|ll|}
\hline Nomenclature & \\
MWCNTs & Multi Walled Carbone Nanotubes \\
SWCNTs & Single Walled Carbone Nanotubes \\
$\lambda$ & Air-Fuel Equivalence Ratio \\
\hline
\end{tabular}

\section{Experimental method}

A scheme of the experimental layout is shown in Fig. 1. In order to run the experiments, air and methane are separately introduced into the mixture chamber (see Fig. 1) through different ducts. The amount of the two gaseous species have to ensure a final pressure equal to 6 bar into the mixture chamber and the desired air-methane ratio at the same time. During tests, six values of air-methane ratio have been tested. From the mixture chamber, the air-methane mixture is introduced into the combustion chamber. A solenoid valve (see Fig. 1) is used to determine the amount of air-methane mixture introduced into the combustion chamber (see Fig. 1) in order to reach the desired pressure $(3$ bar) at the experiment onset. During this phase, the air-methane mixture flux also moves the desired amount of MWCNTs, previously introduced into the holder (see Fig. 1), into the combustion chamber. In all tests, $20 \mathrm{mg}$ samples of MWCNTs with $75 \%$ of ferrocene by weight were used. The combustion chamber, made in low-carbon steel, has a cylindrical shape with inner diameter equal to $53 \mathrm{~mm}$ and length equal to $270 \mathrm{~mm}$. The chamber is 
equipped with a piezoresistive pressure sensor (KELLER type PA-21Y 0-200 bar). Pressure signal has been sampled at $2.5 \mathrm{kHz}$ using a NI cDAQ 9178 acquisition board with a NI 9205 AI module, and processed through the LabVIEW NI software. A longitudinal quartz rectangular optical access has been mounted (172 mm length x $37 \mathrm{~mm}$ height x $20 \mathrm{~mm}$ thickness) along the combustion chamber. By means of a CCD Memrecam GX-1F High Speed positioned in front of the quartz optical access, the images of the combustion process have been acquired with a frame rate equal to $2.5 \mathrm{kHz}$ for an overall recording time equal to $1.8 \mathrm{~s}$.

An automotive spark plug (NGK model 4983 DCPR7E-N-10) and a Xe camera flash (SIGMA model EF610DGST) have been placed aside the combustion chamber, with the aim of comparing the combustion process observed igniting the mixture with the spark plug with the combustion process obtained igniting the mixture with MWCNTs. Both ignition sources (the camera flash and the spark-plug) have been activated by a relay, remotely controlled by means of a DIO 5 Volt TTL High Speed NI 9401 module. Once the desired pressure ( 3 bar) was reached into the combustion chamber, the solenoid valve automatically closed and, after a constant delay, a TTL signal was generated for activating either the camera flash or the spark plug. The energy released by the flash and the spark plug are respectively about 5 and $20 \mathrm{~J}$.

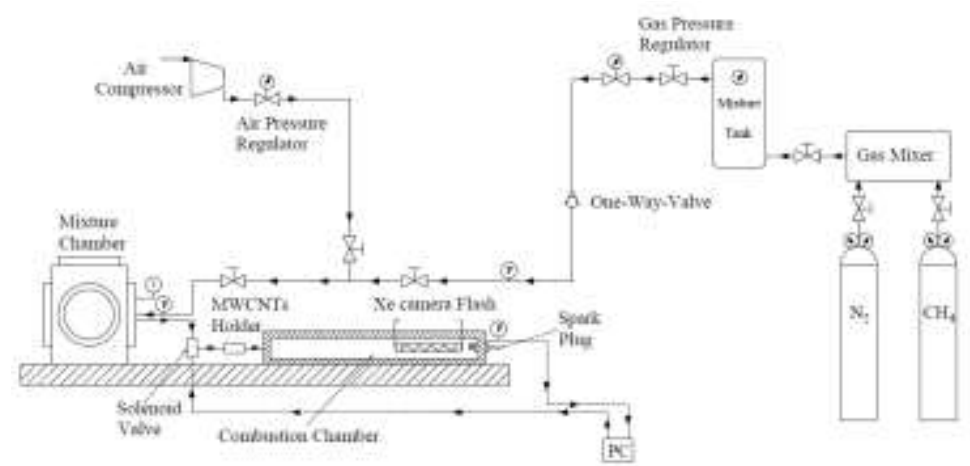

Fig. 1. Scheme of the experimental layout

\section{Results and discussion}

\subsection{Combustion Analysis}

As previously said, during tests both ignition system (MWCNTs and spark plug) and the air-fuel equivalence ratio $\lambda$ have been varied. $\lambda$ is defined as:

$$
\lambda=\frac{(A / F)_{a c t}}{(A / F)_{s t}}
$$

where $(A / F)_{a c t}$ is the ratio between air and methane mass actually feeding the combustion chamber, while $(A / F)_{s t}$ is the stoichiometric ratio between air and methane. Based on this definition, $\lambda=1$ represents an actual stoichiometric mixture, while $\lambda>1$ indicates a mixture as leaner as $\lambda$ exceeds 1 . In this work, $(A / F)_{s t}$ has been fixed equal to 17.4, while $\lambda$ has been varied on six levels in the range 1-2. The combustion characterization is based on the measurement of the combustion pressure. For example, in figure 2, combustion pressure curves are plot obtained igniting with MWCNTs or with the spark plug an airmethane mixture with $\lambda$ equal to 1.02 . It is possible to see that, after the trigger signal occurrence (flash or 
spark activation), the pressure into the combustion chamber increases from its initial value ( 3 bar) due to combustion development, reaches a peak value and then decreases due to heat transfer to the environment through the chamber walls. From now on, the difference between the pressure initial value ( 3 bar $)$ and the pressure peak value will be referred to as delta pressure.

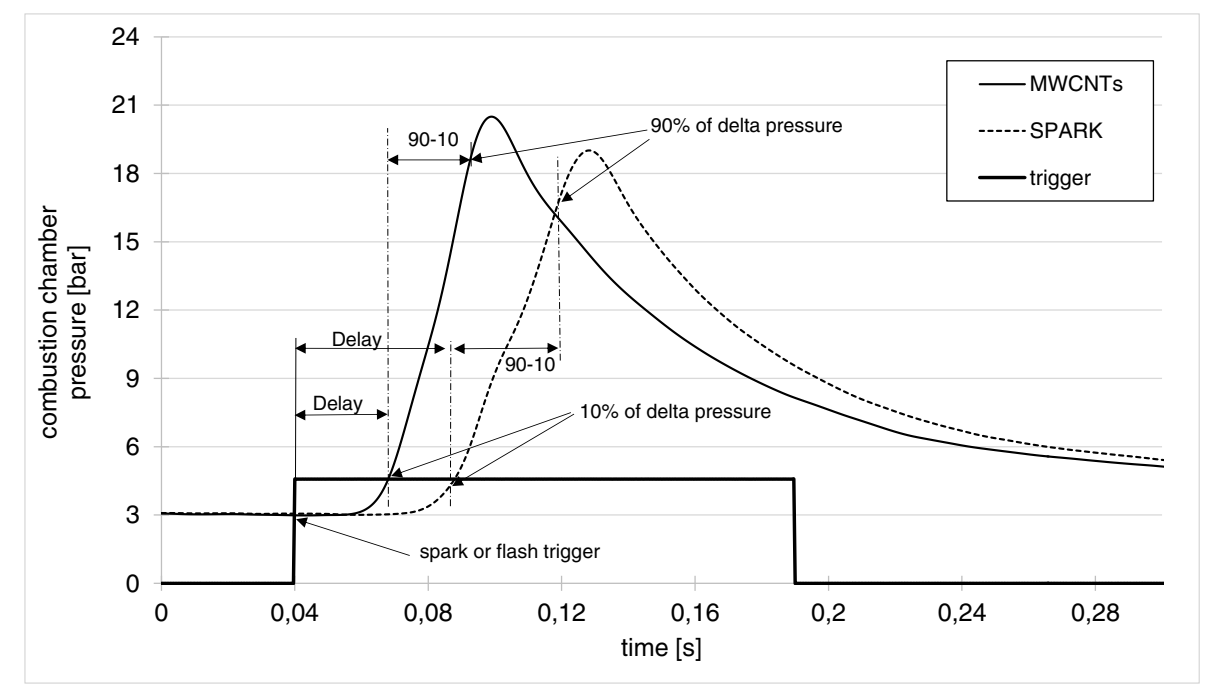

Fig. 2. Combustion pressure with MWCNTs photo-ignition (20 mg of MWCNTs containing $75 \%$ ferrocene by weight) and with spark ignition of an air-methane mixture $(\lambda=1.02)$

From the combustion pressure curves, it was possible to estimate:

- the ignition delay, defined as the difference between the time at which the combustion pressure had reached a value equal to $10 \%$ of the delta pressure and the time at which the trigger has been activated;

- the combustion duration, defined as the difference between the time instants at which the combustion pressure had reached a value respectively equal to $90 \%$ and $10 \%$ of the delta pressure.

From Fig. 2, it can be observed that the combustion triggered by the MWCNTs photo-ignition evolves more rapidly and exhibits a shorter ignition delay and a higher peak pressure than in the case the mixture is ignited by a spark plug.

In Fig. 3 the pressure curves related to MWCNTs-ignited (a) and spark-ignited (b) combustion processes are shown, in both cases for different values of $\lambda$. Comparing Fig. 3 (a) and (b) it is evident that the peak of combustion chamber pressure reached igniting the mixture with MWCNTs is always higher or comparable to that observed using the spark plug. Increasing $\lambda$, i.e. burning leaner mixtures, the pressure peak decreases and is delayed. It can be also qualitatively argued that, with MWCNTs, both ignition delay and combustion duration are shorter. This conclusion is confirmed by Fig. 4, in which the ignition delay and the combustion duration as previously defined are reported for all tests.

In Fig. 5 two series of pictures related to the combustion process with MWCNTs (top row) and spark plug (bottom row) are reported. Data refer to $\lambda=1.35$ and the time interval between a picture and the following is equal to $5 \mathrm{~ms}$. It is clearly visible that, in the process with MWCNTs, the combustion is faster and the combustion chamber is wholly interested by the presence of flame starting from the $5^{\text {th }}$ frame. In the 
process with spark plug, on the contrary, the propagation of a flame front can be recognized in all the pictures; moreover, the light radiated by the flame is weaker.

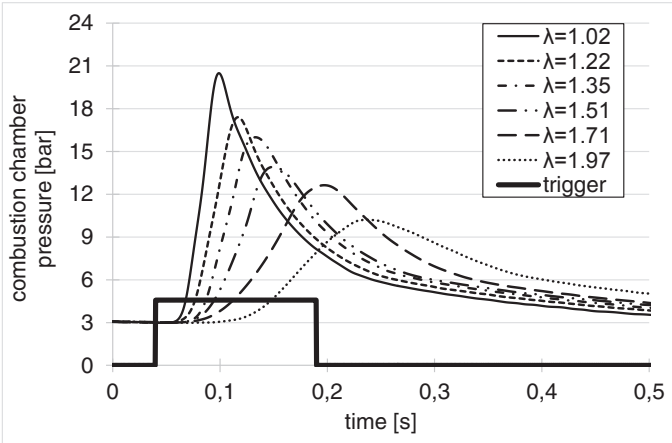

(a)

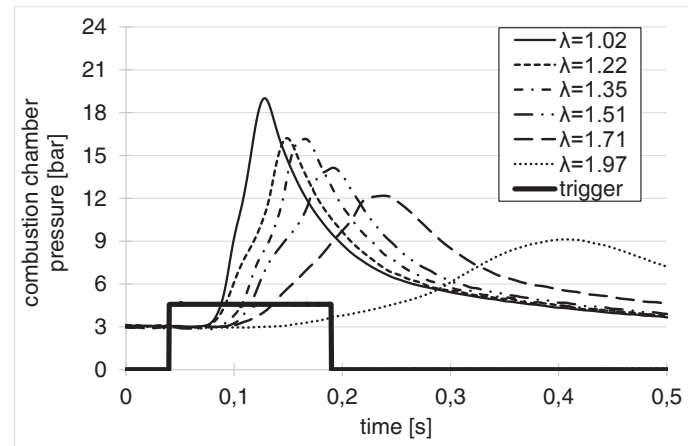

(b)

Fig. 3. Combustion pressure with MWCNTs (a) and spark (b) ignition for different values of $\lambda$

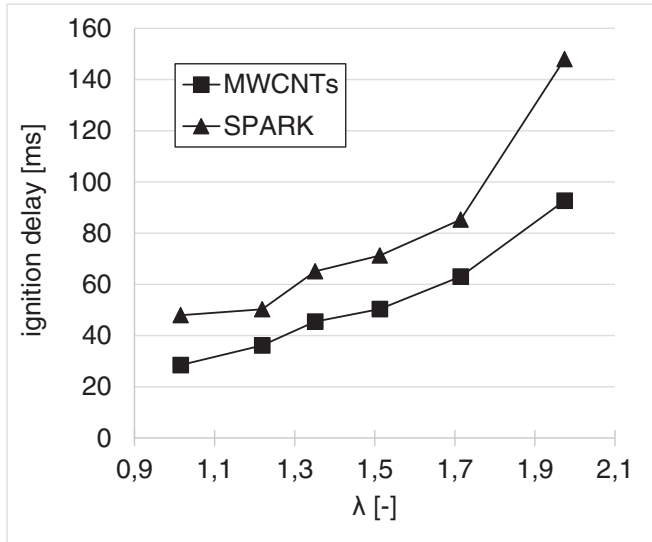

(a)

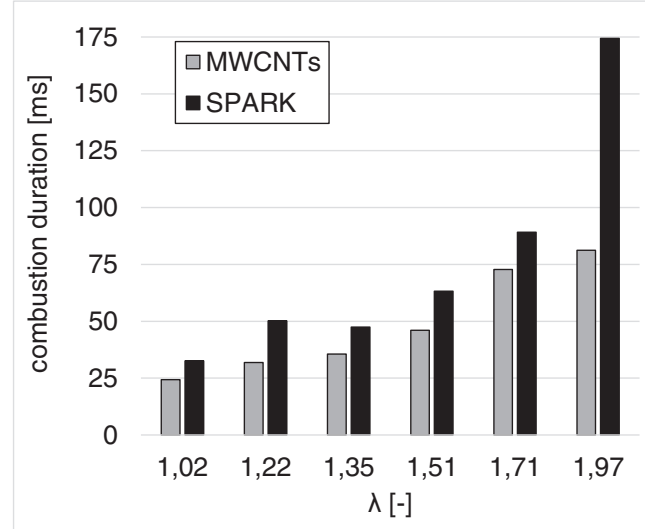

(b)

Fig. 4. Ignition delay (a) and combustion duration (b) with MWCNTs and spark ignition for different values of $\lambda$

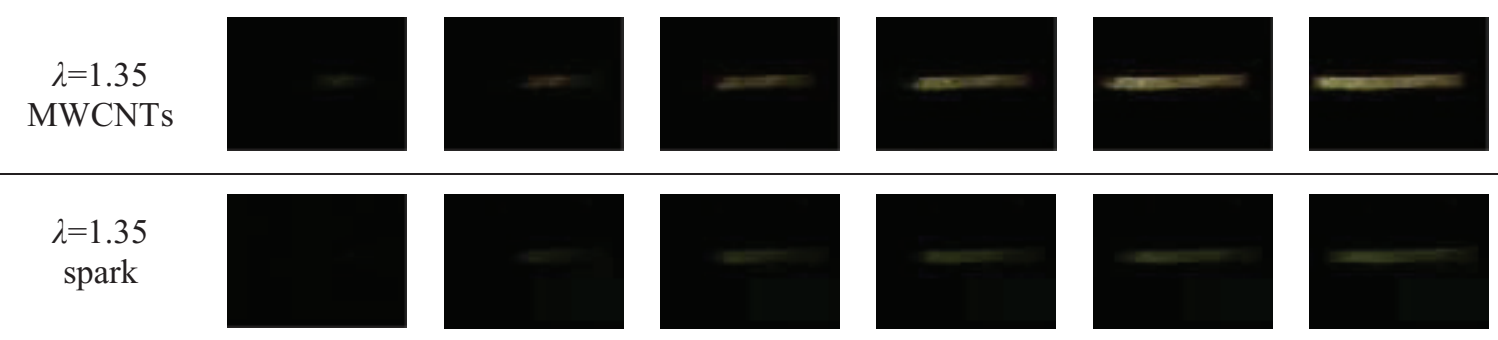

Fig. 5. Pictures of the combustion process at $\lambda=1.35$; comparison between MWCNTs photo-ignition and spark ignition 


\section{Conclusion}

In this paper, a new ignition system is proposed and tested on an air-methane mixture, based on the exposition of Multi-Walled Carbon NanoTubes (MWCNTs) to a camera flash. During the tests, $20 \mathrm{mg}$ samples of MWCNTs with $75 \%$ ferrocene by weight were suspended in the air-methane mixture into a constant-volume combustion chamber and exposed to a camera flash. This combustion process has been compared with the one obtained with a traditional spark ignition system for different values of airmethane equivalence ratios.

Combustion pressure curves acquired during the tests show that MWCNTs-ignited combustion processes exhibit a more rapid rise in pressure and a higher peak pressures, which corresponds to shorter ignition delays and combustion durations when compared with the combustion processes obtained with a traditional spark plug. It can be deduced that the ignition system with MWCNTs leads to more ignition nuclei, burning simultaneously and so speeding up the combustion process. Furthermore, high-speed camera images show that MWCNTs-ignited combustion process is more volumetrically distributed into the combustion chamber, differently than the flame front propagation observed with the spark ignition.

\section{References}

[1] Carlucci AP, Laforgia D, Motz S, Saracino R, Wenzel SP: "Advanced closed loop combustion control of a LTC diesel engine based on in-cylinder pressure signals", Energy Conversion and Management 77 (2014) 193-207 (DOI: 10.1016/j.enconman.2013.08.054) ISSN: 0196-8904.

[2] Ajayan PM, Terrones M, A. de la Guardia, Huc V, Grobert N, Wei BQ et al., Science 296 (2002) 705.

[3] Bockrath B, Johnson JK, Sholl DS, et al., Science 297 (2002) 192.

[4] Smith J, Wincheski B, Namkung M, Crooks R, Louie R, Mat. Sci. Eng. A 358 (2003) 384-389.

[5] Chehroudi B, Vaghjiani GL, Ketsdever A. Method for distributed ignition of fuels by light sources. US Patent 7,517,215 B1;April 14,2009.

[6] Chehroudi B, Vaghjiani GL, Ketsdever A. Apparatus for distributed ignition of fuels by light sources. US Patent 7,665, 985 B; February 23,2010.

[7] Chehroudi B, Badashan A, Danczyk SA, Morgan C. Ignition characteristics of Single-Walled Carbon Nanotubes (SWCNTs) utilizing a camera flash for distributed ignition of liquid sprays. Joint Army-Navy-NASA-Air Force (JANNAF) Propulsion Meeting (JPM) and 6th Modeling and Simulation/4th Liquid Propulsion/3ed Spacecraft Propulsion Joint Sub-committee Meeting. Orlando, Florida; December 8-12, 2008.

[8] Chehroudi B, Danczyk SA. A novel distributed ignition method using single-walled carbon nanotubes (SWCNTs) and a lowpower flash light. Global Powertrain Congress, World Powertrain Conference \& Exposition. Novi, Michigan; September 19-21, 2006.

[9] Chehroudi B, Danczyk SA, Ketsdever A, Vaghjiani GL. A low power, novel ignition of fuels using Single-Walled Carbon Nanotubes (SWCNTs) and a camera flash. 53ed JANNAF Interagency Propulsion Committee Meeting, 2nd Liquid Propulsion, 1st Spacecraft Propulsion Subcommittee. Monterey, California; December 5-8, 2005.

[10] Chehroudi B, Danczyk SA. An innovative ignition method using SWCNTs and a camera flash. Nano Science and Technology Institute (NSTI), Nanotechnology Conference and Trade Show. Anaheim, California; May 8-12; 2005.

[11] Berkowitz AM, Oehlschlaeger MA, Proceedings of the Combustion Institute 33 (2011) 3359-3366.

\section{Biography}

Luciano Strafella graduated in 2013 in Mechanical Engineering at University of Salento. Since February 2014, he is a Ph.D. student of XXIX cycle in "Engineering of Complex Systems" at University of Salento. His research field is combustion improvement and emissions reduction in traditional and dual-fuel compression ignition engines. 